\title{
COMUNICAÇÃO ORGANIZACIONAL, MARKETING E ENDOMARKETING: FERRAMENTAS PARA O TRABALHO DO PSICOLOGO ORGANIZACIONAL
}

\author{
Nilmaer Souza da Silva. Anne Karoline Bertacco da Silva, Jacqueline S. Pinheiro de Almeida, Milene \\ Egea Semensato. Gelise Soares Alfena. \\ Universidade do Oeste Paulista - UNOESTE, Curso de Psicologia, Presidente Prudente, SP. E-mail: nilmaer@unoeste.br
}

\begin{abstract}
RESUMO
A realidade contemporânea nas organizações é pautada em um cenário competitivo. A comunicação eficaz implica, entre outras coisas, na maximização da eficiência institucional, bem como na redução das redes de rumores, que afetam, além do trabalhador, os resultados organizacionais. O presente trabalho teve por objetivo associar a eficiência da comunicação, o marketing e o endomarketing como ferramentas de gestão para o psicólogo organizacional. Utilizou-se da pesquisa bibliográfica como metodologia. Constatou-se as essenciais diferenças desses fenômenos e suas aplicabilidades no mundo organizacional, como ferramentas para o psicólogo organizacional. Foi possível concluir que o feedback destaca-se dentro da comunicação, pois o mesmo enriquece o desempenho das equipes, proporcionando que todos possam entender quais ações serão realizadas dentro da organização. Diante das dificuldades de comunicação interna, surge o endomarketing que, objetivamente, é uma estratégia de comunicação focada no cliente interno, indispensável para o sucesso da organização.
\end{abstract}

Palavras-chave: Clientes internos. Feedback. Gestão. Psicologia Organizacional.

\section{ORGANIZATIONAL COMMUNICATION, MARKETING AND ENDOMARKETING: TOOLS FOR WORK ORGANIZATIONAL PSYCHOLOGIST}

\begin{abstract}
The contemporary reality in organizations is guided on a competitive setting. Effective communication involves, among other things, maximizing the institutional efficiency as well as the reduction of network rumors that affect both, the employee and the organizational results. This study aimed to associate the efficiency of communication, marketing, and endomarketing as management tools for organizational psychologist. It was used the bibliographich research as methodology. It was possible to find the essential differences of these phenomena and their applicability in the organizational world, as tools for organizational psychologist. It was possible to conclude that the feedback stands out within communication, because it enhances the performance of the teams, providing that everyone can understand what actions will be carried out within the organization. In the face of internal communication difficulties, endomarketing arises objectively, that is a focused communication strategy on the internal cliente, indispensable for the success of the organization.
\end{abstract}

Keywords: Internal customers. Feedback. Management. Organizational Psychology. 


\section{INTRODUÇÃO E OBJETIVO}

A administração estratégica é um processo utilizado para melhorar os resultados da organização, por meio do qual se deve analisar o ambiente, estabelecer diretrizes, formular estratégias que sejam implementadas de modo que contribuam para o bom desenvolvimento e crescimento da organização e, consequentemente, aumentem sua vantagem competitiva.

Destaca-se, no contexto da administração estratégica, focada à psicologia organizacional, a apropriação de conceitos, a priori, ligados apenas à Administração, tais como: comunicação, marketing e endomarketing. Esses fenômenos, como poderá ser visto ao longo do trabalho, podem ser utilizados como ferramentas de gestão para os psicólogos organizacionais.

Dentro do campo da psicologia organizacional, o psicólogo atua em empresas, indústrias e organizações com diversas práticas. Bock, Furtado e Teixeira (2008) consideram que a atuação do profissional irá depender do que se enfatiza ou se delimita, o psicólogo pode estar mais atento à saúde dos colaboradores, às relações entre as pessoas, ao processo de seleção de funcionários, realizando treinamento, ou seja, o trabalho do psicólogo organizacional envolve tarefas que decorrem da preocupação com tudo o que envolve o processo de trabalho. Já Bastos e GalvãoMartins (1990) afirmam que o Psicólogo Organizacional ocupa-se de: planejamento ambiental; elaboração de políticas de recursos humanos; desenvolvimento de equipes multidisciplinares; avaliação, aperfeiçoamento, e reciclagem profissional; condução de processos de recrutamento e seleção, intervenções coletivas, dentre tantas outras.

Todas as responsabilidades do psicólogo organizacional, acima citadas, harmonizam-se na criação de uma esfera em que as organizações e os indivíduos possam prosperar mutuamente. Com base nesse contexto, esta pesquisa teve como objetivo desvendar os conceitos da comunicação, do marketing e do endomarketing, associando-os à atuação do psicólogo nas organizações, como ferramentas de gestão no processo de comunicação empresarial.

\section{REFERENCIAL TEÓRICO COMUNICAÇÃO}

De acordo com estudos realizados por Oliveira (apud VANIN e RANCICH FILHO, 2013, p. 14) a administração estratégica atua com o olhar no presente, no futuro e na direção dos recursos empresariais de forma otimizada com a realidade ambiental, com a maximização das relações interpessoais. Tento em vista as relações interpessoais sob a perspectiva estratégica, Robbins, Timothy e Sobral (2010) articulam que a comunicação deficiente é a principal fonte de conflitos interpessoais no trabalho, sendo assim, para se ter sucesso na vida profissional é fundamental uma boa capacidade de comunicação. Além disso, quem comunica algo precisa transmitir a informação e garantir que ela seja compreendida pelo receptor, fato este que garante uma boa comunicação.

A comunicação perfeita, se existisse, ocorreria quando um pensamento ou ideia fosse transmitido de uma pessoa para outra de tal forma que a figura mental percebida pelo receptor fosse idêntica à do emissor. Embora um tanto elementar na teoria, a comunicação perfeita nunca é obtida na prática [...]. (Robbins, Timothy e Sobral, 2010, p. 325).

Cunha e colaboradores (apud MACÊDO, 2012, p. 27) afirmam em seus escritos que "as pessoas tendem a qualificar como um comunicador eficaz aquele que sabe ser um bom ouvinte [...] e é capaz de fazer perguntas inteligentes que ajudam a evitar mal-entendidos". A partir disso, surge a importância do feedback na comunicação, uma das competências de maior relevância que enriquece o desempenho das equipes. Segundo Zarifian (apud MACÊDO, 2012, p. 28) o feedback proporciona que as pessoas compreendam as ações que serão realizadas na organização, de modo que todos alcancem um objetivo comum. 
É importante que o feedback aconteça de maneira construtiva, ou seja, que aconteça no momento adequado, que seja descritivo, proporcional aos fatos relatados e seja focado no futuro, além disso, o gestor deve-se lembrar que elogios podem ser feitos em público, mas repreensões não. (MACÊDO, 2012). Pode-se perceber que dentro de uma organização, a boa comunicação é fundamental. Várias são as direções da comunicação dentro da organização, podendo fluir no sentido vertical (ascendente ou descendente) ou horizontal.

Comunicação descendente é aquela que parte dos níveis mais elevados para o setor operacional, incluindo instruções de trabalho, mensagens, fornecimento de feedback. Robbins, Timothy e Sobral (2010, p. 328) apontam que "os melhores comunicadores explicam as razões por trás das comunicações descendentes, mas também solicitam a seus subordinados que comuniquem seus anseios e opiniões". Comunicação ascendente diz respeito às informações que partem do nível operacional em direção aos gestores em forma de sugestões e melhorias. Outro tipo de comunicação é a lateral, onde as mensagens são transmitidas no mesmo nível, alcançando diferentes setores. Dentro da organização, a comunicação pode ser feita de forma oral, escrita e não verbal.

A partir do momento em que diversas pessoas se relacionam existe a comunicação informal, dentro de uma organização, esse tipo de comunicação denomina-se rede de rumores. A informação que percorre a rede de rumores vai ser mantida "enquanto os desejos e expectativas que geram a incerteza não forem atendidos ou enquanto a ansiedade não for reduzida". (ROBBINS, TIMOTHY E SOBRAL, 2010, p. 333). O fato é que a rede de rumores não é totalmente ruim, a partir dela os gestores podem ter uma ideia daquilo que os colaboradores pensam da organização, considerando importante o que eles pensam e ajudando a controlar ansiedades.

Assim, o gestor deve estar sempre atento às conversas de corredor como uma espécie de termômetro da importância atribuída ao conteúdo dessas conversas, até para poder desmentir eventuais informações sem fundamento ou esclarecer pontos obscuros. (MACÊDO, 2012, p. 37)

\section{MARKETING E ENDOMARKETING}

De acordo com Ogden (2007), marketing é a ciência que estuda, entende e monitora mercados, o que muda é sua finalidade. O conceito estabelece que uma empresa deva satisfazer os desejos e as necessidades do consumidor em troca de lucro, direcionando seus esforços a fim de dar a seus clientes serviços e produtos que eles desejam ou de que necessitam. A partir das dificuldades de comunicação interna, surge o endomarketing, segundo Macêdo $(2012$, p. 40) ele [...] "adapta inúmeras ferramentas da área mercadológica para melhorar o nível das mensagens a serem passadas aos diferentes públicos internos da empresa". Endomarketing é uma estratégia de gestão que visa o cliente interno. A origem da palavra endomarketing está estruturada na composição do prefixo grego éndon, ou seja, movimento para dentro, esse termo foi concebido em meados da década de 1980. Bekin (1990 apud CANGUSSU et al, 2015, p.02), enfatiza que "endomarketing é, portanto, um conjunto de ações de marketing institucional dirigida para o público interno (colaboradores, fornecedores, acionistas, vendedores)".

Pode-se então, segundo Bekin (1990 apud CANGUSSU 2015, p. 02), definir endomarketing como sendo ações de marketing, gerenciadas e dirigidas ao público interno das organizações e empresas focadas no lucro. Brum (1998 apud CANGUSSU et al, 2015) define o endomarketing como "sendo conjunto de ações utilizadas por uma empresa para promover a sua própria imagem a funcionários e seus familiares". Pode-se então perceber que são as ações mais simples, como o reconhecimento e a informação que fazem com que o público interno encontre estímulo para desempenhar um bom trabalho. Segundo Cangussu et al (2015), o endomarketing surge com a necessidade de atrair seus clientes internos, gerando então resultados positivos para as organizações e podendo assim atrair clientes externos. Cangussu et al (2015), enfatizam que 
funcionários satisfeitos e comprometidos com a empresa, transmitem isso para o externo, vendendo assim uma boa imagem da empresa, já um funcionário insatisfeito com as condições de trabalho, irá fazer uma propaganda negativa da empresa.

Endomarketing na visão de Cangussu et al (2015), é uma postura estratégica que pretende mostrar aos colaboradores a importância de um bom atendimento ao consumidor. Inkotte (2000) define como sendo um relacionamento semelhante para empresa/clientes e empresa/funcionários, transformando os esforços decorrentes do trabalho em valor para a organização e satisfação para o funcionário. Para Inkotte (2000 p.98) endomarketing consiste em "identificar as necessidades e desejos a partir do próprio cliente interno, para satisfazê-lo eficaz e eficientemente, buscando o estímulo à compra (do produto-empresa) e a fidelização deste segmento".

O endomarketing de acordo com Cangussu et al (2015, p. 03), envolve temas como: "motivação dos funcionários, comunicação, comprometimento, valores, ferramentas de marketing e satisfação do cliente final". Chiavenato (2004, apud CANGUSSU et al, 2015, p. 04), pondera que as "organizações são constituídas de pessoas e dependem delas para atingir seus objetivos, [...] para as pessoas, as organizações representam o meio através do qual elas podem alcançar seus objetivos pessoais".

O endomarketing é uma das mais importantes estratégias de recursos humanos que visa ao crescimento da organização, não apenas firmada em pilares econômicos, mas sociais e humanos (CANGUSSU et al, 2015). Diante disso, pode se concluir que o endomarketing, segundo Cangussu et al (2015), é um elemento indispensável para o sucesso de qualquer empresa, que se baseia primeiramente na conquista do público interno para atuar em conjunto junto ao mercado consumidor. Dias (2010), acrescenta que alguns programas podem ser implementados num projeto de endomarketing, esses programas vão depender tanto da organização como também do nível de entendimento dos funcionários sobre a estratégia do processo. 0 endomarketing na visão de Dias (2010), não apenas trabalha com o desenvolvimento de estímulos motivacionais no campo psicológico, mas também com a introdução de estímulos materiais como, prêmios e gratificações, mas a empresa tem que estar ciente dos riscos, pois dinheiro e prêmios são motivadores de curta duração e podem gerar efeitos contrários.

Diante de vários programas de endomarketing que podem ser implantados na organização, o importante é saber caracterizá-los de acordo com a organização e adaptá-los à realidade e o investimento justificado através dos resultados (DIAS, 2010).

METODOLOGIA

O instrumento de coleta de dados foi à pesquisa bibliográfica pois, segundo Köche $(2009, p$. 122), "a pesquisa bibliográfica é a que se desenvolve tentando explicar um problema, utilizando o conhecimento disponível a partir das teorias publicadas em livros ou obras congêneres".

Dessa maneira, os autores valeram-se da pesquisa bibliográfica, consultando, notadamente, livros e periódicos online, em plataformas digitais, realizando buscas por artigos científicos disponíveis na Base de dados da Biblioteca Virtual em Psicologia Brasil (BVS-Psi Brasil), entre outras mantidas pela Comissão de Aperfeiçoamento de Pessoal do Nível Superior - CAPES. As palavras chaves utilizadas na pesquisa foram: Clientes Internos; Feedback; Gestão; Psicologia Organizacional; Endomarketing, além de outras.

"A pesquisa é um procedimento reflexivo, sistemático, controlado e crítico que permite descobrir novos fatos ou dados, soluções ou leis, em qualquer área do conhecimento" (RAMPAZZO, 2005, p. 49). Portanto, ela é importante para identificar o que e como se desenvolverá. Nesse sentido, importa afirmar que este estudo foi concebido com a Abordagem Qualitativa. Esta, de acordo com Rampazzo (2005, p. 58): 
"[...]busca uma compreensão particular daquilo que estuda: o foco da sua atenção é centralizado no específico, no peculiar, no individual, almejando sempre a compreensão e não a explicação dos fenômenos estudados".

Por fim, oferece interesse destacar que cerca de trinta textos foram selecionados, sendo que houve aproveitamento de quatorze destes. Com isso, foi possível analisar vários conceitos que permitiram a exploração deste tema, os quais merecem destaque: Marketing; Endomarketing; Psicólogo Organizacional e Rede de Ruídos.

\section{RESULTADOS}

Os resultados demonstram que a rede de rumores, proveniente da comunicação ineficaz pode ser minimizada por meio da adoção do endomarketing, especialmente na área de recursos humanos. Não se vislumbra o atendimento de necessidades de uma determinada parcela da sociedade - público externo - sem o comprometimento do público interno. A busca da disseminação da comunicação eficaz é uma tarefa atinente, especialmente, ao psicólogo organizacional. Da mesma forma, a comunicação eficaz pode ser conseguida utilizando-se do endomarketing, notadamente, como estratégia de gestão pelas áreas de recursos humanos, cujo departamento abriga o psicólogo organizacional. Nesse sentido, o endomarketing atinge um valor não econômico, mas deve ser tido como uma coluna social e humano no contexto organizacional.

\section{DISCUSSÕES}

Enquanto o marketing pode ser compreendido como a ciência que estuda os mercados, suas tendências e as necessidades dos clientes externos à organização, de acordo com o que preconiza Ogden (2007), o endomarketing é a ciência que busca contemplar as necessidades dos clientes internos (CANGUSSU et al, 2015).

As organizações são compostas por pessoas, sendo assim o psicólogo com seu conhecimento sobre o comportamento humano e suas necessidades contribui de diversas maneiras dentro das organizações. A área de atuação é definida segundo Yamamoto (1987 apud BASTOS, GOLDIM, 2010, p. 175) "como um conjunto de habilidades que o psicólogo está habilitado a fazer".

De acordo com o Conselho Federal de Psicologia (2016), o psicólogo dentro de suas especificidades profissionais atua com o objetivo de promover, em seu trabalho, o respeito à dignidade e integridade do ser humano. Dentro das organizações o psicólogo atua individualmente ou em equipe multiprofissional, onde quer que se deem as relações de trabalho nas organizações sociais formais ou informais, visando à aplicação do conhecimento da Psicologia para a compreensão, intervenção e desenvolvimento das relações e dos processos intra e interpessoais, intra e intergrupais e suas articulações com as dimensões política, econômica, social e cultural.

Pinheiro, Mario e Giacomini (2012, p. 125), enfatizam que dentro das organizações existem uma gama de atividades em que o psicólogo pode contribuir, como Recrutamento e seleção de pessoal, aplicação de testes psicológicos, treinamento e desenvolvimento, avaliação de desempenho, de potencial, de performance, coaching, atendimento aos colaboradores, diagnóstico organizacional, programas de qualidade, análise de cargos e salários, entrevista de desligamento, pesquisa de clima, programa de qualidade de vida no trabalho (QVT), trabalhos de saúde mental do trabalhador, prevenção em acidentes de trabalho, entre outros.

O cenário atual exige que o Psicólogo organizacional tenha uma visão pluralista e interprofissionalidade, é necessário que se tenha uma compreensão multidisciplinar dos eventos da empresa e repense suas alternativas e abordagens (IEMA, C. R. D., 1999, p. 41). lema (1999) pondera que o Psicólogo deve ter uma atuação que leve em conta uma participação transparente nas rotinas administrativas, o autor enfatiza ainda que "a procura de um desempenho inovador 
conduz o psicólogo a posições de liderança, na coordenação de órgãos de Recursos Humanos, em atividades ligadas às estratégias de empresa, comumente visando o aumento da participação" (IEMA, C. R. D., 1999, p. 37). O Psicólogo deve levar em consideração a cultura e/ou conjuntos de valores da organização que estabelecem à ética e a prática, devem desenvolver ideias criativas e úteis para empresa, tendo em mente que a criatividade e inovação dependem do senso critico e interesse pelo trabalho (IEMA, 1999).

Após a vasta pesquisa bibliográfica, foi possível constatar que o comunicador eficaz é também um bom ouvinte, sendo aquele que evita situações de conflitos e redes de rumores, tornando o ambiente de tralhado mais apropriado para o desenvolvimento organizacional (MACÊDO, 2012). A capacidade de comunicação deve ser perseguida por todos os profissionais que desejam alavancar as suas carreiras, pois os conflitos interpessoais são decorrentes, por vezes, das deficiências na comunicação (ROBBINS; TIMOTHY; SOBRAL, 2010). O psicólogo organizacional deve buscar promover, dentro das suas responsabilidades, um ambiente coeso e ético, permitindo uma comunicação eficaz e, quando esta não ocorrer, realizar o instituto do feedback, o que enriquece o desempenho das equipes (MACÊDO, 2012).

Nesse enredo, considerando a amplitude da pesquisa aqui realizadas, verifica-se que o endomarketing, ao possibilitar uma comunicação interna que sensibilize os colaboradores de uma determinada organização, a compreenderem, de maneira mais acurada, os objetivos organizacionais e o papel de cada indivíduo, sua importância e que isso pode ser harmonizar, também, seus objetivos organizacionais, mitiga a criação de conflitos internos, as redes de rumores e, sobretudo, pode criar um ambiente apropriado para uma comunicação eficaz.

\section{CONSIDERAÇÕES FINAIS}

Esta pesquisa permite, ao leitor, an overview sobre como o endomarketing pode ser empregado como uma ferramenta de apoio às responsabilidades de um psicólogo organizacional. O conteúdo aqui apresentado foi uma amostra do assunto, diante do mais aprofundado material apresentado nas referências, que podem servir de fontes de pesquisas para o público correlato.

A pesquisa realizada para a confecção deste trabalho oportunizou o entendimento da atuação do psicólogo dentro da organização, sobre o marketing, o endomarketing e como a comunicação interfere tanto positivamente quanto negativamente no contexto organizacional.

Considera-se que essa pesquisa possa contribuir para profissionais que atuam no âmbito organizacional, podendo assim ampliar a compreensão a respeito do tema abordado, que é relevante e contemporâneo.

\section{REFERÊNCIAS}

BASTOS, A. V.B; GALVAO-MARTINS, A. H.C. O que pode fazer o psicólogo organizacional. Psicol. cienc. prof., Brasília, v. 10, n. 1, p. 10-18, 1990.

BASTOS, A; GONDIM, S. O trabalho do psicólogo no Brasil. Porto Alegre: Artmed, 2010. Disponível em: <https://books.google.com.br/books?id=KTUlYpk_6ylC\&pg=PA174\&hl=pt-

BR\&source=gbs_toc_r\&cad=3\#v=onepage\&q\&f=false>. Acesso em: 04 de jan. 2016.

CANGUSSU, C. H. et al. ENDOMARKETING: Utilização como ferramenta de crescimento organizacional. Rev. Conexão Eletrônica - Três Lagoas, MS - Volume 12 - Número 1 - Ano 2015.

CONSELHO FEDERAL DE PSICOLOGIA. Apresenta: Atribuições Profissionais do Psicólogo no Brasil. Disponível em: <cfp.org.br/wp-content/uploads/2008/08/atr_prof_psicologo.pdf>. Acesso em: 04 de jan. 2016. 
DIAS, J. G. G. Endomarketing: uma ferramenta indispensável para a gestão de pessoas nas organizações. 1. Ed. São Paulo: Livro Pronto, 2010.

IEMA, C. Um estudo teórico sobre a formação do Psicólogo Organizacional no Brasil. Psicologia Teoria e Prática, São Paulo, SP, 1999. Disponível em: <http://www.mackenzie.br/fileadmin/Editora/>. Acesso em: 04 jan. 2016.

INKOTTE, A. L. Endomarketing: elementos para a construção de um marco teórico. 2000.144f. Dissertação apresentada ao curso de Pós-Graduação em Engenharia de Produção, da Universidade Federal de Santa Catarina, como requisito parcial para a obtenção de grau de mestre em engenharia de produção.

KÖCHE, J. C. Fundamentos de metodologia científica: teoria da ciência e iniciação à pesquisa. 26. ed. Petrópolis: Vozes, 2009.

MACÊDO, I. I. de. Gestão de pessoas. Rio de Janeiro: Editora FGV, 2012.

OGDEN, J. R.; CRESCITELLI, E. Comunicação integrada de marketing: conceitos, técnicas e práticas. 2. Ed. São Paulo: Pearson Prentice Hall, 2007. PINHEIRO, L, R, S., MARIO, C., GIACOMINI, M. A ATUAÇÃO DO PSICÓLOGO ORGANIZACIONAL E DO TRABALHO NO NORTE DO RIO GRANDE DO SUL. 2012, Disponível em: $<$ www.uricer.edu.br/site/pdfs/perspectiva/136_313.pdf>. Acesso em; 04 de jan. de 2016.

RAMPAZZO, L. Metodologia científica: para alunos dos cursos de graduação e pós-graduação. 2. ed. São Paulo: Edições Loyola. 2005.

ROBBINS, S. P.; TIMOTHY, A. J.; SOBRAL, F. Comportamento organizacional. 14. Ed. São Paulo: Pearson Prentice Hall, 2010.

VANIN, J. A e RANCICH FILHO, N. A. Administração estratégica. Curitiba: Intersaberes, 2013. 